Article

\title{
The Impact of a Twelve-Month Comprehensive Program of Cognitive Training for Alzheimer Patients: A Pilot Study
}

\author{
Álvaro Rodríguez-Mora ${ }^{1,2, *(\mathbb{C})}$, José R. Cordón ${ }^{3}\left[\right.$, Gabriel G. de la Torre ${ }^{2,3}{ }^{(-)}$and \\ José M. Mestre 1,2,3 (D) \\ 1 Instituto Universitario para el Desarrollo Social y Sostenible, Universidad de Cádiz, Jerez de la Frontera, \\ 11406 Cádiz, Spain; josemi.mestre@uca.es \\ 2 Department of Psychology, Universidad de Cádiz, Puerto Real, 11519 Cádiz, Spain; gabriel.delatorre@uca.es \\ 3 Instituto de Investigación e Innovación Biomédica de Cádiz, Universidad de Cádiz, 11009 Cádiz, Spain; \\ josercordon@gmail.com \\ * Correspondence: alvaro.rodriguezmora@uca.es; Tel.: +34-956-016-218
}

Received: 1 September 2020; Accepted: 29 October 2020; Published: 3 November 2020

\begin{abstract}
Research has shown that non-pharmacological therapies can be useful in the treatment of Alzheimer's disease (AD), significantly delaying cognitive decay. However, most AD interventions did not last beyond six months. Hence, little is known about the effect of these programs in the AD patients after six months of treatment. The purpose of this study was to evaluate the efficacy of the twelve-month Comprehensive Program of Cognitive Training (CPCT) for a sample of AD patients and to compare the results with the average annual rate of change. Thirty-nine AD patients participated in the study. The CPCT consists of a set of cognitive stimulations, intervention in activities of daily life (ADL), and motor training for 12 months. All patients were evaluated at baseline and in three-month intervals via the Mini Mental State Examination (MMSE), the Cambridge Cognitive Examination (CAMCOG), the Lawton Instrumental Activities of Daily Living Scale (IADL), and the Global Deterioration Scale (GDS). After CPCT implementation, there were no significant differences in the MMSE, IADL, and GDS evaluations between baseline and twelve months. Concerning the CAMCOG evaluation, there was no significant difference between the baseline and sixth-month assessments. Overall, the participants' cognitive functioning did not decline when compared to the average annual rate of change. The CPCT extends the benefit of non-pharmacological interventions for AD patients to twelve months. Its implementation might provide the patients' relatives with some guarantee concerning the delay of the disease. Future research may investigate the efficacy of the CPCT in comparison with a control group and over a more extended period.
\end{abstract}

Keywords: dementia; Alzheimer's disease; non-pharmacological therapies; cognitive stimulation therapy; cognitive training; follow-up AD intervention

\section{Introduction}

Nowadays, non-pharmacological interventions for Alzheimer's disease (AD) are increasing with different levels of outcomes [1,2]. These approaches include AD cognitive interventions (ADCI). Clare and Woods (2004) described three main methods of ADCI: (a) cognitive stimulation requires the patients to carry out mental and social activities in a group situation [3-7]; (b) cognitive training involves cognitive exercises that use pen and paper or a computer [8]; and (c) cognitive rehabilitation uses individualized interventions to address the patient's fundamental difficulties and goals $[9,10]$. Choi and Twamley [11] and Moro et al. [12] pointed out that cognitive stimulation, cognitive training, or cognitive rehabilitation influence learning capacity in mild cognitively impaired (MCI) and AD 
patients, which is an essential mediator for these cognitive approaches. However, it is unclear how long they must be implemented to be effective.

Most of the mental function improvements from ADCI are reported in earlier AD stages [3,4,13-15]. Most of these treatments lasted for six months or less [10,12,16], and, rarely up to twelve months [17]. Thus, little is known about these mental benefits beyond six months. These treatments have a wide array of significant benefits for AD patients [18], but these benefits vary over time. Bahar-Fuchs, Clare, and Woods [19] reported that one reason for these variations could be that AD patients experience a rapid improvement at the beginning of the treatment that subsequently reaches a peak and then starts to deteriorate again. ADCI or another non-pharmacological treatment can also improve other functions. For instance, the activities of daily living (ADL, for example being autonomous for eating or dressing) improved and/or were maintained during the first six months of the intervention $[19,20]$.

Graessel et al. [17] implemented a long-term cognitive intervention for 61 patients with dementia. Their study also evaluated a control group that received standard care. Patients who underwent cognitive treatment exhibited a significant improvement in personal functioning compared to patients in the control group. Similar research reported that targeting cognitive function also positively influences the neuropsychiatric symptoms of mild-stage AD [21], reduces depression symptoms [19,22], and improves personal autonomous functioning $[8,19,20,23]$. Thus, a program that lasts at least six months improves cognitive and behavioral function and ADL in AD patients $[11,16,24,25]$.

While improvements have been repeatedly observed within the first three months of an ADCI and continue for some time after that $[6,15,16,25,26]$, most interventions usually do not exceed six months $[5,7,12,16,18]$. Thus, there are sparse data about what happens after the sixth month. Therefore, it is necessary to know to what extent individual variability affects the potential benefits of ADCI. Thus, there is a need for additional studies that consider the potential benefits of ADCI or non-pharmacological interventions beyond six months $[17,20,23]$.

To determine the efficacy of a non-pharmacological and global intervention, Luttenberger et al. [20] performed a six-month follow-up randomized-controlled study with German nursing-home residents with primary degenerative dementia (Mini Mental State Examination (MMSE) < 24). At six months, the motor stimulation activities of daily living and cognitive stimulation (MAKS) protocol improved both social function and instrumental capabilities in the residents compared with those in the control group. This study suggests that at six months, cognitive and functional measures may reflect the onset of the asymptotic decline of moderate dementia residents. However, there are no significant differences at this point. The same group of authors tested the MAKS in a twelve-month randomized-controlled trial (RCT) with similar participants (moderate dementia symptoms). For the control group, patients in the experimental group exhibited delayed cognitive impairment and improved ADL performance [17]. However, the authors did not include information about measures at baseline or before interventions. Thus, Graessel et al. [17] recommended a follow-up period beyond six months to determine whether there is some stabilization of the effects of global intervention in dementia (even in AD) patients. To determine the prolonged influence of MAKS, Luttenberger, Hofner, and Graessel [27] examined effects ten months after the MAKS program ended. Sixty-one primary degenerative dementia patients were evaluated (the final sample was 52) under an RCT method. The MAKS group $(n=30)$ was treated for $2 \mathrm{~h}$, six days a week for 12 months, and the control group (CG, $n=22)$ received standard nursing home care. During the intervention, the MAKS group maintained their ADL capabilities and cognitive function. However, after the MAKS program ended, both groups exhibited ADL and cognitive function deterioration. Nevertheless, the MAKS group remained significantly higher in ADL measures compared to control patients even ten months after the end of the MAKS program. They concluded that preventing functional decline "as long as possible" [27] (p. 151) should be the goal of interventions.

Muñiz et al. [23] performed a randomized study to examine long-term (three-year) Alzheimer disease mild impairment results of a cognitive-motor stimulation intervention in AD (CMSI). The CMSI group (nbaseline $=44$ (4 patients did not receive treatment); n1-year follow-up $=40, \mathrm{n} 2$-year 
follow-up $=39$, and n3-year follow-up $=36$ ) received a multimodal intervention for AD patients and CG (nbaseline = 40; n1-year follow-up = 40, n2-year follow-up = 37, and n3-year follow-up = 32) just received standard support. CMSI participants exhibited better functional benefits compared to controls, and AD participants' partners accepted the program well. Despite these promising effects (cognitive, ADL, mood, and motor improvements), the authors raised "questions and concerns regarding the long-term adequacy of CMSI in terms of cognition" (p. 302), especially in MCI and AD patients.

Although cognitive intervention provides benefits for AD patients at least in the short-term [24], there are some problems when comparing different studies. This fact makes it difficult to assess their impacts on the AD sufferers. For example, in ADCI experiences, we found wide variability in the type, content, and duration of the intervention $[15,18,24,28]$. A large number of studies focused only on one type of intervention (cognitive stimulation, cognitive training, or cognitive rehabilitation). Some revised interventions stimulated AD patients, both cognitively and through improved ADL, but not in an integrated or comprehensive way [14,25,29]. Most studies limited cognitive stimulation programs to six months, while others lasted for only a few weeks $[5,10,12,13,16]$. These studies have shown initial improvements in AD patients, however little is known about the efficacy of these non-pharmacological programs when they last beyond the six months. It is necessary to explore, using an initial pilot study, to what extent the earlier improvements on autonomy and quality of life of the AD sufferer may be statistical and significantly better than the annual rate of deterioration for AD patients without any intervention [24]. Some studies have indeed argued a need to assess the efficacy of comprehensive programs of a more prolonged nature $[16,17,24]$.

Therefore, to check the benefits of long-term non-pharmacological treatment for AD patients, it would be necessary to conduct an intervention program for at least twelve months and compare the results with the expected rate of deterioration $[17,20]$. To explore these issues mentioned above, we implemented a pilot study (with no control group) to test the benefits of the twelve-month Comprehensive Program of Cognitive Training (CPCT) [15] for AD patients. This twelve-month integrated program addresses the cognitive functions, $\mathrm{ADL}$, and the psychomotricity of people suffering mild, moderate, and severe AD. The first objective was to verify whether the application of the program had a positive influence on the progression of dementia and, furthermore, to see whether it maintains the scores of the cognitive state and the instrumental activities of daily life (IADL). We hypothesized that there would be no significant difference between the baseline and twelve-month scores (see below for the measures used in the study). A further aim of the research was to investigate whether CPCT promoted cognitive status maintenance in $\mathrm{AD}$ patients when compared to the expected rate of change in the disease. We hypothesized that the program would improve participants' scores compared to the established annual impairment rate. Due to ethical and contractual considerations, a comparison with the average yearly rate of change was used as a measure of efficacy instead of a control group, as the intervention could not stop the usual care being applied to the patients.

\section{Methods}

\subsection{Participants}

The participants were selected from AD Spanish patients living in a residential home in Cádiz and patients, who were attending a day center in Seville (Spain). These patients were diagnosed with $\mathrm{AD}$ and met the diagnostic criteria of the Diagnostic and Statistical Manual of Mental Disorders Fifth Edition (DSM-5) and the National Institute of Neurological and Communicative Disorders and Stroke and the Alzheimer's Disease and Related Disorders Association (NINCDS-ADRDA).) The inclusion criteria were as follows: (1) Mini-Mental State Examination (MMSE) $\geq 9$ points and $\leq 26$ points; (2) Global Deterioration Score (GDS) > 6 points; (3) not in a state of altered consciousness; and (4) a level of mild autonomy. Exclusion criteria were as follows: (1) severe ADL deficit; (2) severe behavioral disorders; and (3) severe medical conditions that impede attending the program. 
A baseline assessment was performed that established three assessment areas, which covered cognitive status, ADL, and impairment stages. According to their impairment stage, we distributed the AD participants into three groups according to the cutoff points from the GDS. We administered the intervention.

\subsection{Measures}

\subsubsection{Cognitive Measures}

The MMSE [30] is used for clinically monitoring patients with impairment and as evidence in cognitive screening. The Cambridge Cognitive Examination (CAMCOG) [31] assesses orientation, language, memory, attention/concentration, praxis, touch perception, calculation, abstract thinking, visual perception, and time calculation. The CAMCOG has proven to be a useful tool for detecting early $\mathrm{AD}$ and prodromal stages of $\mathrm{AD}$ [32].

\subsubsection{Activities of Daily Living}

The Lawton Instrumental Activities of Daily Living Scale (IADL) is an appropriate instrument to assess independent living skills [33]. It provides clear evidence of the functional and impairment levels of people who have dementia.

\subsubsection{Impairment Classification}

The GDS classifies the patient in seven stages according to her/his level of impairment [34].

\subsection{Design}

We selected AD Spanish patients living in a residential home in Cádiz and patients who were attending a day center in Seville (Spain). These patients were diagnosed with $\mathrm{AD}$ and met the diagnostic criteria of the DSM-IVR and the National Institute of Neurological and Communicative Disorders and Stroke and the Alzheimer's Disease and Related Disorders Cognitive measures. The MMSE [30] is used for clinically monitoring patients with impairment and as evidence in cognitive screening. A baseline assessment was performed with MMSE, CAMCOG, IADL, and GDS. The CPCT was applied for $3 \mathrm{~h}$ a day, five days a week for twelve months. Assessments at the sixth, ninth, and twelfth months were conducted with the same tests that were applied at baseline.

\section{СРCT}

The CPCT was organized with three thematic modules: cognitive stimulation, ADL, and psychomotricity training (Table 1). Cognitive stimulation was designed as four-week blocks that were applied each month. The ADL and psychomotricity training were intended to be applied every two weeks. Each thematic module was repeated over the twelve-month period. The structure of the sessions for each workshop was determined by three aspects: function, objective, and activity. The functional aspect was determined by cognitive ability, ADL, or psychomotricity ability stimulation. The objective aspect consisted of the target that was intended to be reached by this function. The activity aspect was the exercise to be performed to attain the targets proposed for that function. In the cognitive area, we worked reality orientation and visual, auditory, and affective memory. These two functions were worked for four weeks. In addition to orientation and memory, specifically in the first week, we also worked on comprehension, expressive language, and verbal fluency. We also worked on recognition. In the second week, we worked on ideological and constructional praxis. In the third week, we worked on abstraction capacity. In the fourth week, we worked on attention and mental calculation. Every cognitive session lasted $45 \mathrm{~min}$. 
Table 1. Outline of the Comprehensive Program of Cognitive Training (CPCT). The four-week program was repeated every month for one year.

\begin{tabular}{|c|c|c|c|}
\hline & Cognitive Stimulation & ADL Training & $\begin{array}{l}\text { Psychomotricity } \\
\text { Training }\end{array}$ \\
\hline Week 1 & $\begin{array}{ll}\text { - } & \text { Reality orientation } \\
\text { - } & \text { Visual, auditive, and } \\
\text { affective memory } \\
\text { - } \quad \text { Language (reading, } \\
\text { - } \quad \text { Rriting, verbal fluency) } \\
\text { Recognition }\end{array}$ & $\begin{array}{ll}\text { - } & \text { Using money } \\
\text { - } & \text { Using the telephone } \\
\text { - } & \text { Frooming objects } \\
\text { - } & \text { Using a watch } \\
\text { - } & \text { Ordering sequence } \\
& \text { of dressing } \\
\text { - } & \text { Simulation of buying }\end{array}$ & $\begin{array}{ll}\text { - } & \text { To jump } \\
\text { - } & \text { To walk } \\
\text { - } & \text { Circuit training } \\
\text { - } & \text { Gym } \\
\text { - } & \text { Different } \\
& \text { motor abilities }\end{array}$ \\
\hline Week 2 & $\begin{array}{ll}\text { - } & \text { Reality orientation } \\
\text { - } & \text { Visual, listening, and } \\
\text { affective memory } \\
\text { - } & \text { Constructional and } \\
\text { ideational praxis }\end{array}$ & $\begin{array}{ll}\text { - } & \text { Using money } \\
\text { - } & \text { Using the telephone } \\
\text { - } & \text { Frooming objects } \\
\text { - } & \text { Using a watch } \\
\text { - } & \text { Ordering sequence } \\
& \text { of dressing } \\
\text { - } & \text { Simulation of buying }\end{array}$ & $\begin{array}{ll}\text { - } & \text { To jump } \\
\text { - } & \text { To walk } \\
\text { - } & \text { Circuit training } \\
\text { - } & \text { Gym } \\
\text { - } & \text { Different } \\
& \text { motor abilities }\end{array}$ \\
\hline Week 3 & $\begin{array}{ll}\text { - } & \text { Reality orientation } \\
\text { - } & \text { Visual, listening, and } \\
& \text { affective memory } \\
\text { - } & \text { Abstraction ability }\end{array}$ & $\begin{array}{ll}\text { - } & \text { Using money } \\
\text { - } & \text { Using the telephone } \\
\text { - } & \text { Food objects } \\
\text { - } & \text { Using a watch } \\
\text { - } & \text { Ordering sequence } \\
\text { - } & \text { of dressing } \\
\text { Simulation of buying }\end{array}$ & $\begin{array}{ll}\text { - } & \text { To jump } \\
\text { - } & \text { To walk } \\
\text { - } & \text { Circuit training } \\
\text { - } & \text { Gym } \\
\text { - } & \text { Different } \\
& \text { motor abilities }\end{array}$ \\
\hline Week 4 & $\begin{array}{ll}\text { - } & \text { Reality orientation } \\
\text { - } & \text { Visual, listening, and } \\
& \text { affective memory } \\
\text { - } & \text { Attention } \\
\text { - } & \text { Mental calculation }\end{array}$ & $\begin{array}{ll}\text { - } & \text { Using money } \\
\text { - } & \text { Using the telephone } \\
\text { - } & \text { Frooming objects } \\
\text { - } & \text { Using a watch } \\
\text { - } & \text { Ordering sequence } \\
& \text { of dressing } \\
\text { - } & \text { Simulation of buying }\end{array}$ & $\begin{array}{ll}\text { - } & \text { To jump } \\
\text { - } & \text { To walk } \\
\text { - } & \text { Circuit training } \\
\text { - } & \text { Gym } \\
\text { - } & \text { Different } \\
& \text { motor abilities }\end{array}$ \\
\hline
\end{tabular}

ADL, activities of daily living.

For the ADL, each week, we worked on using money, using the telephone, grooming objects, food objects, using a watch, ordering sequence of dressing, and simulation of buying. Every session of the ADL program lasted $30 \mathrm{~min}$.

Finally, in the motor program, we worked weekly on jumping, walking, circuit training, gym, and different motor abilities. In this case, every session lasted $15 \mathrm{~min}$. For details of the program, see Rodríguez-Mora [15].

\subsection{Statistical Analysis}

Since parametric assumptions for statistical analysis were not met in all cases, Friedman's repeated-measures analysis of variance (ANOVA) was used to analyze the impact of the intervention program on the cognitive impairment of the subjects. Wilcoxon tests were used to assess the differences between measures from baseline to the sixth, ninth, and twelfth months, when applicable. At the end of the twelve months, the non-parametric Mann-Whitney $U$ test was used to compare the final average score after CPCT application with the final average score that would have been obtained following an annual deterioration rate. 


\section{Results}

The initial evaluation was carried out on 40 patients with Alzheimer's disease. One of the participants was omitted as he had an MMSE score compatible with mild cognitive impairment. The program was applied to the remaining 39 patients. All of them completed the intervention, and all of them were given the tests in the established follow-ups. In the final sample, $76.9 \%$ were women and $23.1 \%$ were men. The average age was 76.31 (standard deviation $[S D]=7.17$ ) years. The majority $(84.6 \%)$ were from the day center in Seville and $15.4 \%$ were from the residential center in Cádiz. With regard to AD stages, $12.8 \%$ were mild, $71.8 \%$ were moderate, and $15.4 \%$ were moderate-severe. The subdivisions are intended to better characterize the sample but not used for analyses. Table 2 shows the sociodemographic variables of the AD sample. Table 3 shows the mean and SD of the baseline and at 12 months.

Table 2. Sociodemographic variables of the Alzheimer's disease (AD) sample.

\begin{tabular}{ccc}
\hline Characteristics & $\mathbf{N}=\mathbf{3 9}$ & $\mathbf{\%}$ \\
\hline Education & & \\
Uneducated & 2 & 5.1 \\
Primary & 28 & 71.8 \\
Secondary & 8 & 20.5 \\
Superior & 1 & 2.6 \\
Marital status & & \\
Married & 10 & 25.6 \\
Widower & 27 & 69.2 \\
Single & 1 & 2.6 \\
Separated/divorced & 1 & 2.6 \\
Patient lives with & & \\
Spouse & 9 & 23.1 \\
Child/family & 23 & 59 \\
Other & 7 & 17.9 \\
GDS & & \\
3-Mild & 5 & 12.8 \\
4-Moderate & 28 & 15.4 \\
5-Severe & 6 &
\end{tabular}

GDS, Global Deterioration Scale.

Table 3. Mini Mental State Examination (MMSE), Cambridge Cognitive Examination (CAMCOG), and Instrumental Activities of Daily Living (IADL) descriptive statistics among the three groups of AD.

\begin{tabular}{cccc}
\hline & Mild $(\boldsymbol{n}=\mathbf{5})$ & Moderate $(\boldsymbol{n}=\mathbf{2 8})$ & Severe $(\boldsymbol{n}=\mathbf{6})$ \\
\cline { 2 - 4 } & $\boldsymbol{M}(\boldsymbol{S D})$ & $\boldsymbol{M}(\boldsymbol{S D})$ & $\boldsymbol{M}(\boldsymbol{S} \boldsymbol{D})$ \\
\hline MMSE & & & \\
Baseline & $22.60(1.14)$ & $14.72(2.69)$ & $9.57(0.53)$ \\
3 month & $23.80(3.11)$ & $15.66(3.36)$ & $10.57(2.29)$ \\
6 month & $21.80(3.11)$ & $15.51(3.21)$ & $10.14(3.23)$ \\
9 month & $20.0(2.00)$ & $14.85(3.59)$ & $10.00(3.21)$ \\
12 month & $19.40(3.36)$ & $13.88(2.62)$ & $9.42(2.87)$ \\
\hline CAMCOG & & & \\
Baseline & $74.50(9.53)$ & $57.60(11.74)$ & $41.16(11.44)$ \\
3 month & $76.50(8.18)$ & $57.82(14.02)$ & $40.16(12.12)$ \\
6 month & $74.75(8.05)$ & $52.08(15.05)$ & $36.83(13.49)$ \\
9 month & $72.50(8.64)$ & $50.47(14.99)$ & $33.33(14.50)$ \\
12 month & $67.50(9.25)$ & $47.60(16.02)$ & $32.16(15.32)$ \\
\hline IADL & & & \\
Baseline & $3.40(1.09)$ & $2.94(1.44)$ & $1.57(0.78)$ \\
3 month & $3.40(1.09$ & $2.92(1.57)$ & $2.14(1.21)$ \\
6 month & $3.00(0.70)$ & $2.69(1.51)$ & $1.85(1.46)$ \\
9 month & $3.00(0.70)$ & $2.65(1.44)$ & $1.85(1.47)$ \\
12 month & $2.40(0.44)$ & $2.57(1.55)$ & $1.71(1.60)$ \\
\hline
\end{tabular}


Cognitive function decreased. as detected by the MMSE. during the twelve-month program $\left(\chi^{2}(4)=35.37, p<0.001\right)$. Wilcoxon tests with a Bonferroni correction were used to follow up this finding, so all effects are reported at a 0.005 level of significance. Cognitive capacities apparently decreased only from the sixth to twelfth $(T=68, r=0.42)$ and ninth to twelfth month $(T=42.5, r=0.40)$. Further, there were significant differences between the third and ninth $(T=6, r=0.52)$ and third and twelfth months ( $T=37, r=0.71$; Figure 1$)$.

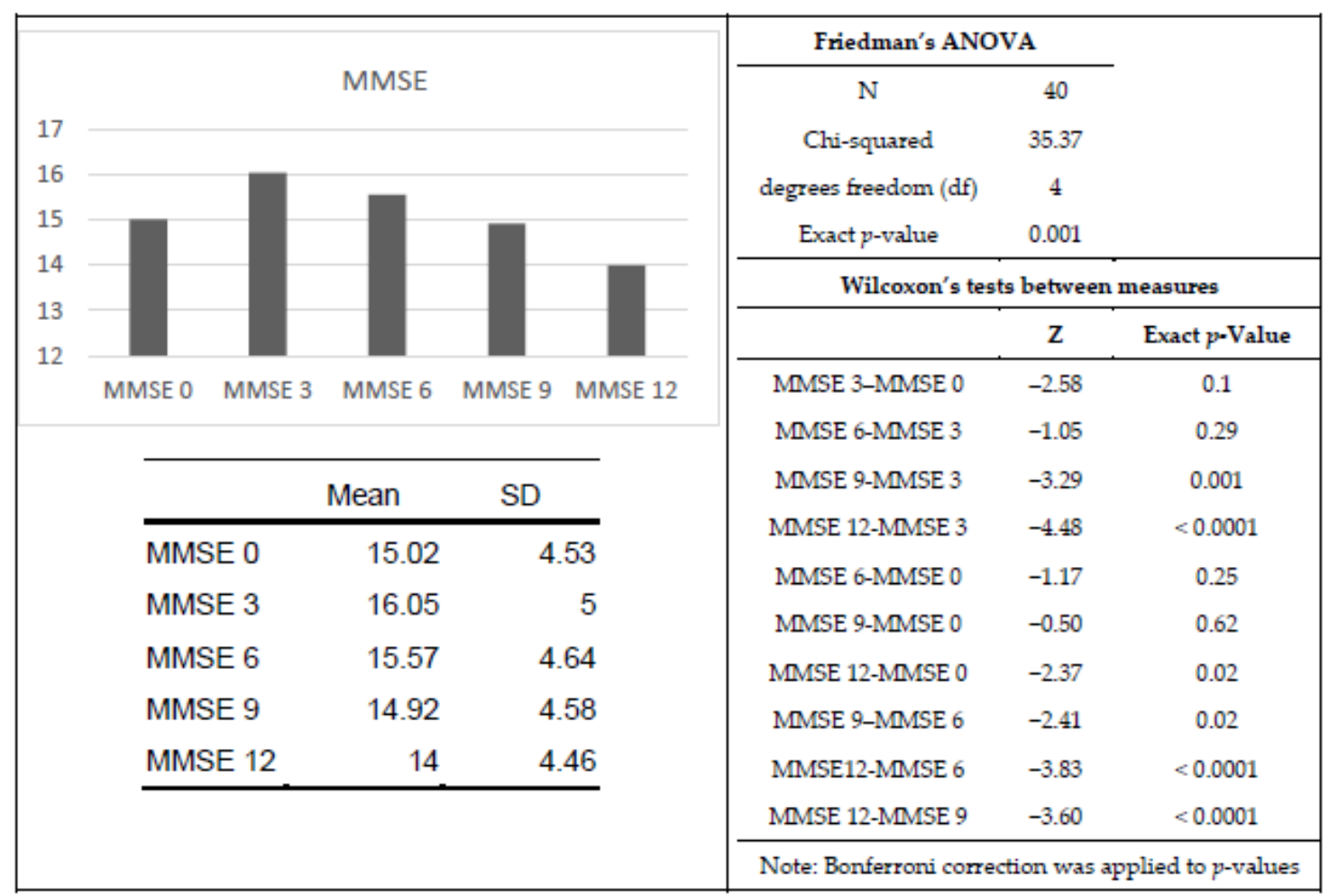

Figure 1. Means, Friedman's ANOVA, and Wilcoxon's tests for MMSE data. For the bar chart, the x-axis represents the analyzed time point (baseline, $3,6,9$ or 12 months), and the $y$-axis represents the average MMSE score.

CAMCOG indicated significant cognitive weakening throughout the twelve-month program $\left(\chi^{2}(4)=32.78, p<0.001\right)$. Wilcoxon tests with a Bonferroni correction were used to examine specific changes over time, so all effects are reported at a 0.008 level of significance. Cognitive capacities decayed from baseline to the ninth month $(T=99.5, r=0.35)$, baseline to the twelfth month $(T=66.5$, $r=0.44)$, the sixth to ninth month $(T=122, r=0.35)$, the sixth to twelfth month $(T=45, r=0.51)$, and the ninth to twelfth month $(T=55, r=0.48)$. There were also significant differences between the sixth and third ( $T=99, r=0.57)$, ninth and third $(T=43, r=0.7)$, and twelfth and third months $(T=24$, $r=0.78$; Figure 2). 


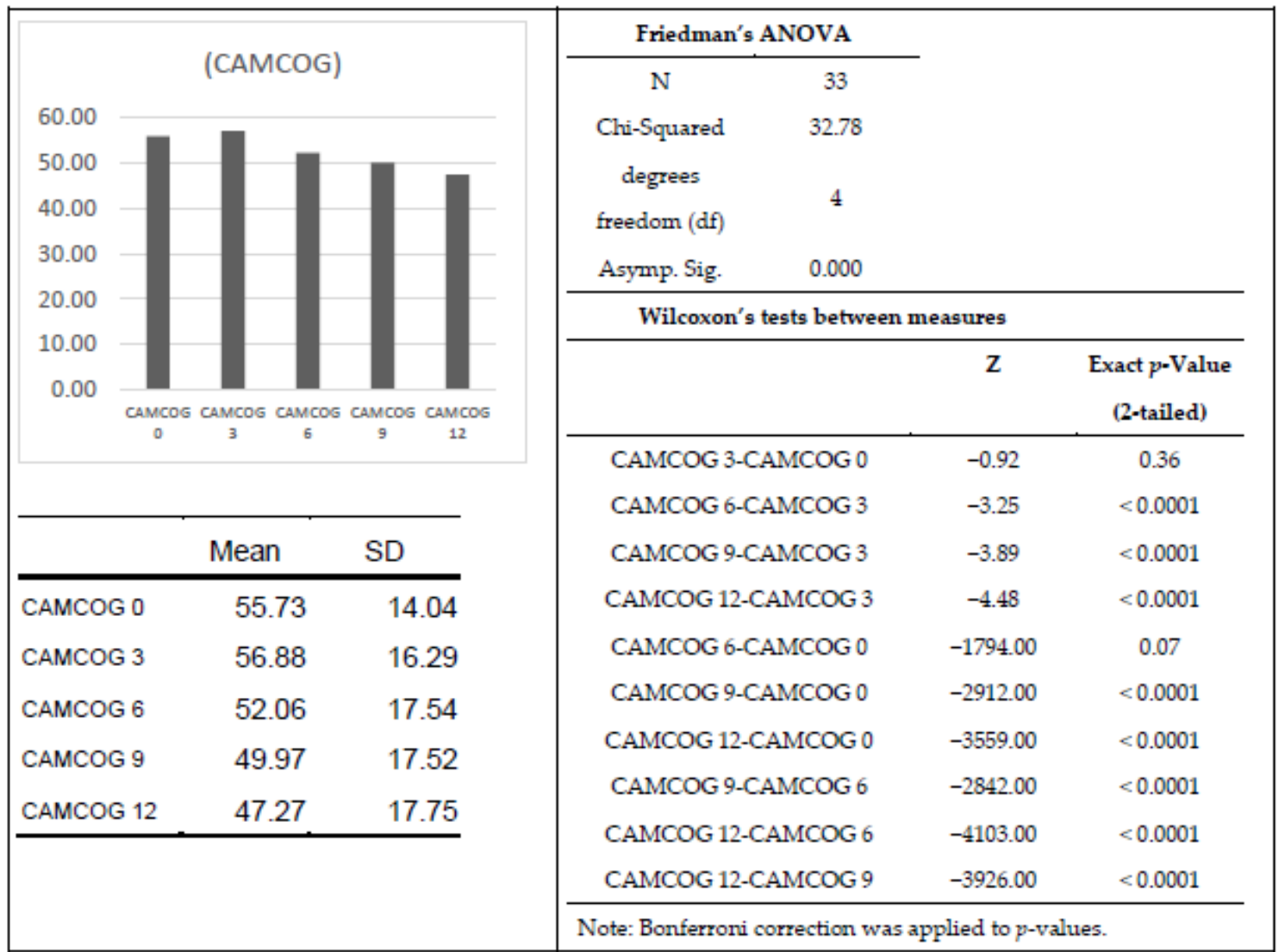

Figure 2. Means, Friedman's ANOVA, and Wilcoxon's tests for CAMCOG scores. For the bar chart, the $x$-axis represents the analyzed time point (baseline, 3, 6, 9 or 12 months), and the y-axis represents the average CAMCOG score.

Likewise, ADL significantly decayed throughout the twelve-month program $\left(\chi^{2}(4)=11.82\right.$, $p=0.01$ ).Wilcoxon tests with a Bonferroni correction were used to examine specific changes over time, so all effects are reported at a 0.005 level of significance. However, no pairs of measures reached this level of statistical significance. With $\alpha=0.05$, there were significant differences from the ninth to third $(T=30, r=0.34)$ and third to twelfth months $(T=20, r=0.42$; Figure 3$)$. 


\begin{tabular}{|c|c|c|c|c|c|c|}
\hline \multicolumn{4}{|c|}{ IADL } & \multicolumn{2}{|c|}{ Friedman's ANOVA } & \\
\hline \multirow{18}{*}{$\begin{array}{l}2.9 \\
2.8 \\
2.7 \\
2.6 \\
2.5 \\
2.4 \\
2.3 \\
2.2 \\
2.1\end{array}$} & & & & $\mathrm{~N}$ & & \\
\hline & & & & Chi-Squared & 11.82 & \\
\hline & & & & degrees & & \\
\hline & & & & freedom (df) & & \\
\hline & & & & Asymp. Sig. & 0.01 & \\
\hline & & & & Wilcoxon's & sts betv & n measures \\
\hline & & & & & Z & Exact $p$-Value \\
\hline & 0 & & IADL 12 & IADL 3-IADL 0 & -0.56 & 0.57 \\
\hline & & Mean & SD & IADL 6-IADL 0 & -0.79 & 0.43 \\
\hline & IADL 0 & 2.73 & 1.42 & IADL 9-LADL 0 & -0.99 & 0.32 \\
\hline & (ADI 3 & 201 & & IADL 12-IADL 0 & -1.55 & 0.12 \\
\hline & IALL J & 2.01 & 1.40 & IADL 6-IADL 3 & -1.85 & 0.06 \\
\hline & IADL 6 & 2.57 & 1.44 & IADL 9-IADL 3 & -2.10 & 0.04 \\
\hline & IADL 9 & 2.55 & 1.4 & IADL 12 -IADL 3 & -2.61 & 0.01 \\
\hline & IADL 12 & 2.39 & 1.48 & IADL 9-IADL 6 & -0.44 & 0.65 \\
\hline & & & & IADL 12-IADL 6 & -1.56 & 0.12 \\
\hline & & & & IADL 12-IADL 9 & -1.61 & 0.11 \\
\hline & & & & $\begin{array}{l}\text { Note: Bonferroni } \\
\text { values. }\end{array}$ & orrectio & vas applied to $p$ - \\
\hline
\end{tabular}

Figure 3. Means, Friedman's ANOVA, and Wilcoxon's tests for IADL scores. For the bar chart, the x-axis represents the analyzed time point (baseline, 3, 6, 9 or 12 months), and the y-axis represents the average IADL score.

Similar to the other measures, GDS was significantly different during the twelve-month program $\left(\chi^{2}(3)=8.84, p<0.05\right)$. Wilcoxon tests with a Bonferroni correction were used to examine specific changes over times, so all effects are reported at a 0.008 level of significance. Cognitive capacities significantly declined only from the sixth to twelfth month $(T=6.5, r=0.32$; Figure 4$)$. 


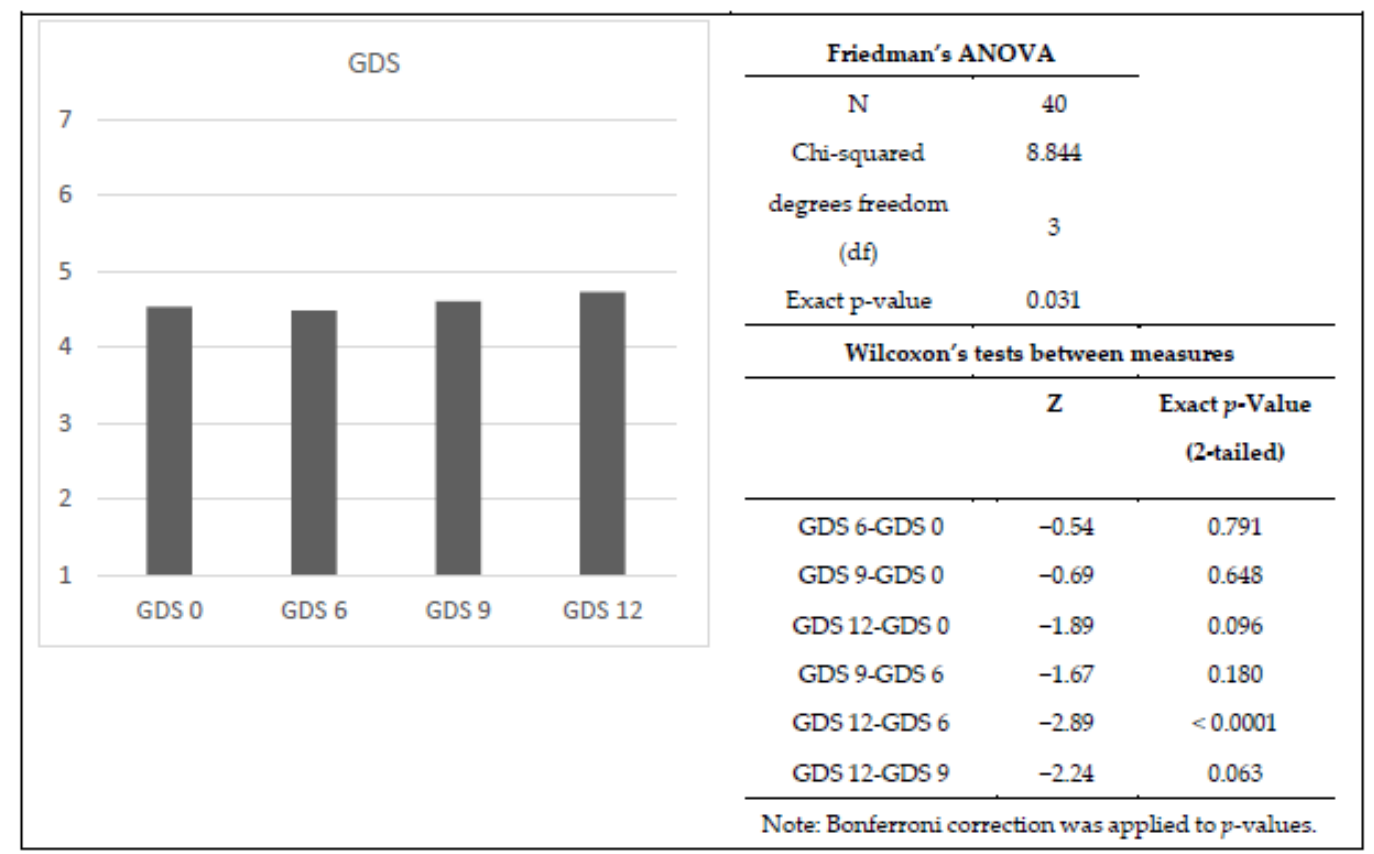

Figure 4. Means, Friedman's ANOVA, and Wilcoxon's tests for GDS scores. For the bar chart, the x-axis represents the analyzed time point (baseline, 3, 6, 9 or 12 months), and the y-axis represents the average GDS score.

A Mann-Whitney $U$ test was performed on the cognitive assessments. Using previous MMSE studies as a comparison [35-37], the Mann-Whitney U test Z-score was -2.31 with $p<0.01$. The CAMCOG score was compared to the annual rate of change established by Ballard et al. [38]. The IADL score was compared to the annual rate of change established by Green et al. [39]. The Mann-Whitney U Test Z-score was -1.40 with $p<0.01$. For the GDS, there were no established references for the annual rate of change. Hence the Mann-Whitney $U$ test was not performed.

\section{Discussion}

Based on the above assessments, twelve-month CPCT application appears to have a positive influence on delaying the cognitive and functional status in AD. The data support our hypothesis that the treatment supported the patient's general state during the twelve months. This result is in line with various studies $[17,19,21,24,27,40,41]$ that delay cognitive function and ADL deterioration in patients with dementia after a twelve-month MAKS application. Our results are consistent with those obtained in other studies where a comprehensive program was applied for twelve months $[17,23,26,27]$. Below we compare our MMSE, CAMCOG, IADL, and GDS assessment results after CPCT application with findings from previous studies.

After CPCT implementation, the difference in MMSE scores between baseline and twelve-month assessments was not statistically significant. Likewise, there were no statistically significant differences after three or six months of intervention, although there was an average increase in MMSE scores. Nevertheless, there were several significant differences between the three-month time points. We can draw several conclusions from these data. First, CPCT could improve cognitive performance in AD patients during the first months of intervention. Our results correlate with Clare et al. [26], who reported a statistically significant positive effect in MMSE scores after three months when applying cognitive rehabilitation. However, the effect was not as potent as we previously expected. We may hypothesize that CPCT generated cognitive overstimulation in the patient's state or an awakening of cognitive functions. However, it is possible to suggest that the program influenced the stability of the cognitive performance of AD participants. Regrettably, due to legal and ethical circumstances, without a control group, we cannot assure any impact of the program, and all our interpretations 
should be taken as tentative. Since there were no significant differences in cognitive status between the baseline and twelve-month assessment, CPCT appears to maintain cognitive status in AD and thus delays its natural progression. The average post-treatment score for the MMSE decreased 1.02 points, from $15.02(\mathrm{SD}=4.53)$ to $14(\mathrm{SD}=4.46)$. This decline was lower compared to the average annual rate of change with no treatment reported by other studies: 3.6 points [42], 2.3 points [37], and 2.2 points [13]. Germain et al. [43] observed a two-point decrease in the MMSE from baseline to twelve months in AD patients subjected to cognitive rehabilitation.

However, these results were not differentiated by the three groups of AD participants. In Table 2, the averages and standard deviations obtained by each group suggest that a higher degree of AD severity negatively influenced the overall CPTC's achievement. With the sample size limitations by group, our main aim was related to the effect of the program on AD patients with mild and moderate AD phases. With these caveats in mind (sample size and no control group), this pilot study may suggest to what extent an implemented program for $\mathrm{AD}$ patients can prolong both their social and cognitive functioning. According to most of the studies reviewed, the effects of the psychological programs do not improve the previous baseline beyond six months.

Nonetheless, further investigations with a larger follow-up ( $>6$ months), larger samples, and a control group can confirm this hypothesis. Finally, we suppose that the significant differences that we observed after the third month could be due to the MMSE score increase at that time. However, since the mean difference between the initial assessment and that in the third month was not statistically significant, we propose this conjecture with caution.

The CAMCOG scores were not statistically significantly different from baseline to six-month CPCT application. However, from the sixth month, the scores decreased until the twelfth month. The annual loss was 8.46 points; this value was significantly different. However, it was lower than the annual deterioration rate of 12-14 points reported by Ballard et al. [38]. These data suggest that the CPCT only maintained cognitive abilities in AD patients during the first six months of intervention.

Nevertheless, it does appear to slow deterioration by twelve months and thus delays cognitive function loss. The lack of a significant effect at twelve months maybe because CAMCOG represents a composite score that evaluates different cognitive functions. If only a subset of functions is particularly modulated by CPCT treatment, the global CAMCOG score would not necessarily reflect this benefit. In future research, it would be interesting to evaluate these functions independently, to determine which are particularly affected by $\mathrm{AD}$ progression and modulated by CPCT.

The twelve-month CPCT application slowed ADL deterioration since it increased the IADL score by 0.34 points compared to baseline. Our increase is better than a reported annual loss of 2.06 points in AD patients without treatment proposed by Green et al. [39]. Although the IADL scores were not significantly different between baseline and twelve months, CPCT intervention stabilized the scores in the first months of application. This finding indicates the protocol may promote autonomy and independence for the $\mathrm{AD}$ patient.

Concerning the GDS assessment, there was no significant difference between the baseline and post-CPCT assessments. The difference in average GDS score from baseline to twelve months was 0.2 points. According to the scale interpretation rules, the participants remained in the same impairment stage after twelve months. Therefore, СРCT appears to have a positive influence on the patient's overall condition; it maintains $\mathrm{AD}$ patients' abilities and delays disease progression.

One of the CPCT's objectives was to solve the methodological problems of the systematization and standardization of AD interventions by developing group and individual activities (Jean et al., 2010). The purpose was to implement planned cognitive rehabilitation to intervene in cognitive functions, $\mathrm{ADL}$, and physical activities that typify the disease progression. Additionally, we wanted to examine the effects of the twelve-month intervention. Several studies have proposed comprehensive interventions similar to CPCT. The CPCT extends the intervention period with certain guarantees in comparison to the study of Farina et al. [8], Capotosto et al. [13], Kurz et al. [16], Clare et al. [10], and Luttenberger et al. [20], where the intervention times ranged from six weeks to six months. Our results also revealed patient 
maintenance after six-month CPCT application. As mentioned above, most cognitive rehabilitation studies only last for six months, although they significantly benefit the patients. CPCT can be positively compared with these comprehensive programs, especially at the cognitive level, where CPCT maintained AD patients' cognitive state and ADL [20]. Thus, cognitive rehabilitation would have a positive effect on dementia after a six-month intervention.

Our study has several limitations that must be mentioned. We designed the CPCT to be a comprehensive twelve-month program that addressed the cognitive function, ADL, and physical capacity of the AD patient. Our work is a pilot study where we attempted to test the effectiveness of CPCT in AD. Therefore, there was no control group. Without the CPCT program, the AD patients in our study would only have access to basic care. In our opinion, it would be unethical to deny the patients access to potentially beneficial treatment. Therefore, we exposed all participants to the intervention. A second limitation was that we did not assess behavioral and psychological symptoms of dementia (BPSD) and quality of life (QoL) in our patients. Although it is integral and may have relevance to assessing CPCT, it was not measured in this study. However, future research may examine this measure. A third limitation was our sample size, which was reduced because of the difficulty of maintaining a large number of participants over twelve months. Therefore, the beneficial results we obtained from the CPCT should be considered in terms of our sample. Finally, the CPCT has no specific program that considers the emotional aspects of AD progression. Future CPCT assessment should take into account the patients' personality and include a specific intervention to assess their emotional health.

In conclusion, CPCT may be suitable for use in patients with mild to moderate-severe AD. It may be beneficial by guaranteeing the $\mathrm{AD}$ patients' relatives the maintenance of their cognitive and functional state for at least six months. After six months, СPCT appears to slow the dementia progression compared to how it progresses without treatment. Our results lead us to consider the possibility of being able to intervene in a more or less positive way in the disease. However, we know that this incidence would only be significant during the first six months, after which cognitive status would decline. We would be unable to inform the AD patient's relatives how long we could affect the cognitive state of their loved one.

Author Contributions: Á.R.-M. designed and led both the intervention and the research. Conceptualization and supervision, Á.R.-M. and J.M.M.; methodology, Á.R.M., J.R.C., G.G.d.l.T. and J.M.M.; formal analysis J.R.C. and J.M.M.; investigation Á.R.-M. and J.M.M.; data curation J.R.C. and Á.R.M.; writing一original draft preparation Á.R.M., G.G.d.l.T. and J.R.C.; writing—review and editing Á.R.-M. and J.M.M.; supervision G.G.d.l.T. and J.M.M. All authors have read and agreed to the published version of the manuscript.

Funding: This research received no external funding.

Conflicts of Interest: The authors declare no conflict of interest.

\section{References}

1. Carrion, C.; Folkvord, F.; Anastasiadou, D.; Aymerich, M. Cognitive Therapy for Dementia Patients: A Systematic Review. Dement. Geriatr. Cogn. Disord. 2018, 46, 1-26. [CrossRef]

2. Huntley, J.D.; Gould, R.L.; Liu, K.; Smith, M.; Howard, R.J. Do cognitive interventions improve general cognition in dementia? A meta-analysis and meta-regression. BMJ Open 2015, 5, e005247. [CrossRef] [PubMed]

3. Hall, L.; Orrell, M.; Stott, J.; Spector, A. Cognitive stimulation therapy (CST): Neuropsychological mechanisms of change. Int. Psychogeriatr. 2012, 25, 479-489. [CrossRef] [PubMed]

4. Spector, A.; Gardner, C.; Orrell, M. The impact of Cognitive Stimulation Therapy groups on people with dementia: Views from participants, their carers and group facilitators. Aging Ment. Health 2011, 15, 945-949. [CrossRef] [PubMed]

5. Spector, A.; Orrell, M.; Woods, B. Cognitive Stimulation Therapy (CST): Effects on different areas of cognitive function for people with dementia. Int. J. Geriatr. Psychiatry 2010, 25, 1253-1258. [CrossRef] [PubMed] 
6. Spector, A.; Woods, B.; Orrell, M. Cognitive stimulation for the treatment of Alzheimer's disease. Expert Rev. Neurother. 2008, 8, 751-757. [CrossRef] [PubMed]

7. Woods, B.; Aguirre, E.; Spector, A.E.; Orrell, M. Cognitive stimulation to improve cognitive functioning in people with dementia. Cochrane Database Syst. Rev. 2012, 2, CD005562. [CrossRef]

8. Farina, E.; Mantovani, F.; Fioravanti, R.; Pignatti, R.; Chiavari, L.; Imbornone, E.; Olivotto, F.; Alberoni, M.; Mariani, C.; Nemni, R. Evaluating two group programmes of cognitive training in mild-to-moderate AD: Is there any difference between a 'global' stimulation and a 'cognitive-specific' one? Aging Ment. Health 2006, 10, 211-218. [CrossRef]

9. Clare, L.; Wilson, B.A.; Carter, G.; Hodges, J.R. Cognitive rehabilitation as a component of early intervention in dementia: A single case study. Aging Ment. Health 2003, 7, 15-21. [CrossRef] [PubMed]

10. Clare, L.; Bayer, A.; Burns, A.; Corbett, A.; Jones, R.; Knapp, M.; Kopelman, M.; Kudlicka, A.; Leroi, I.; Oyebode, J.; et al. Goal-oriented cognitive rehabilitation in early-stage dementia: Study protocol for a multi-centre single-blind randomised controlled trial (GREAT). Trials 2013, 14, 152. [CrossRef]

11. Choi, J.; Twamley, E.W. Cognitive Rehabilitation Therapies for Alzheimer's Disease: A Review of Methods to Improve Treatment Engagement and Self-Efficacy. Neuropsychol. Rev. 2013, 23, 48-62. [CrossRef]

12. Emoro, V.; Condoleo, M.T.; Sala, F.; Pernigo, S.; Moretto, G.; Gambina, G. Cognitive Stimulation in a-MCI. Am. J. Alzheimer's Dis. Other Dementias ${ }^{\circledR}$ 2012, 27, 121-130. [CrossRef]

13. Capotosto, E.; Belacchi, C.; Gardini, S.; Faggian, S.; Piras, F.; Mantoan, V.; Salvalaio, E.; Pradelli, S.; Borella, E. Cognitive stimulation therapy in the Italian context: Its efficacy in cognitive and non-cognitive measures in older adults with dementia. Int. J. Geriatr. Psychiatry 2017, 32, 331-340. [CrossRef]

14. Kurz, A.; Pohl, C.; Ramsenthaler, M.; Sorg, C. Cognitive rehabilitation in patients with mild cognitive impairment. Int. J. Geriatr. Psychiatry 2009, 24, 163-168. [CrossRef] [PubMed]

15. Rodríguez-Mora, A. Evaluación Del Impacto De Un Programa Integral De Psicoestimulación Cognitivo Conductual En Una Muestra De Enfermos De Alzheimer y Demencias Afines. Ph.D. Thesis, Universidad de Cádiz, Cádiz, Spain. 2011.

16. Kurz, A.; Thöne-Otto, A.; Cramer, B.; Egert, S.; Frölich, L.; Gertz, H.J.; Kehl, V.; Wagenpfeil, S.; Werheid, K. CORDIAL: Cognitive Rehabilitation and Cognitive-behavioral Treatment for Early Dementia in Alzheimer Disease: A Multicenter, Randomized, Controlled Trial. Alzheimer Dis. Assoc. Disord. 2012, 26, 246-253. [CrossRef]

17. Graessel, E.; Stemmer, R.; Eichenseer, B.; Pickel, S.; Donath, C.; Kornhuber, J.; Luttenberger, K. Non-pharmacological, multicomponent group therapy in patients with degenerative dementia: A 12-month randomzied, controlled trial. BMC Med. 2011, 9, 129. [CrossRef] [PubMed]

18. Ballard, C.G.; Khan, Z.; Clack, H.; Corbett, A. Nonpharmacological treatment of Alzheimer disease. Can. J. Psychiatry 2011, 56, 589-595. [CrossRef]

19. Bahar-Fuchs, A.; Clare, L.; Woods, R. Cognitive training and cognitive rehabilitation for persons with mild to moderate dementia of the Alzheimer's or vascular type: A review. Alzheimer's Res. Ther. 2013, 5, 35. [CrossRef]

20. Luttenberger, K.; Donath, C.; Uter, W.; Graessel, E. Effects of Multimodal Nondrug Therapy on Dementia Symptoms and Need for Care in Nursing Home Residents with Degenerative Dementia: A Randomized-Controlled Study with 6-Month Follow-Up. J. Am. Geriatr. Soc. 2012, 60, 830-840. [CrossRef]

21. Olazarán, J.; Reisberg, B.; Clare, L.; Cruz, I.; Peña-Casanova, J.; Del Ser, T.; Woods, B.; Beck, C.; Auer, S.; Lai, C.; et al. Nonpharmacological Therapies in Alzheimer's Disease: A Systematic Review of Efficacy. Dement. Geriatr. Cogn. Disord. 2010, 30, 161-178. [CrossRef] [PubMed]

22. Orgeta, V.; Qazi, A.; Spector, A.; Orrell, M. Psychological treatments for depression and anxiety in dementia and mild cognitive impairment: Systematic review and meta-analysis. Br. J. Psychiatry 2015, 207, 293-298. [CrossRef]

23. Muñiz, R.; Serra, C.M.; Reisberg, B.; Rojo, J.M.; Del Ser, T.; Casanova, J.P.; Rodríguez, J.E. Cognitive-Motor Intervention in Alzheimer's Disease: Long-Term Results from the Maria Wolff Trial. J. Alzheimer's Dis. 2015, 45, 295-304. [CrossRef] [PubMed]

24. Aguirre, E.; Woods, R.T.; Spector, A.; Orrell, M. Cognitive stimulation for dementia: A systematic review of the evidence of effectiveness from randomised controlled trials. Ageing Res. Rev. 2013, 12, 253-262. [CrossRef] 
25. Maci, T.; Le Pira, F.; Quattrocchi, G.; Di Nuovo, S.; Perciavalle, V.; Zappia, M. Physical and Cognitive Stimulation in Alzheimer Disease. The GAIA Project. Am. J. Alzheimer's Dis. Other Dementias ${ }^{\circledR}$ 2012, 27, 107-113. [CrossRef]

26. Clare, L.; Kudlicka, A.; Oyebode, J.R.; Jones, R.W.; Bayer, A.; Leroi, I.; Kopelman, M.; James, I.A.; Culverwell, A.; Pool, J.; et al. Individual goal-oriented cognitive rehabilitation to improve everyday functioning for people with early-stage dementia: A multicentre randomised controlled trial (the GREAT trial). Int. J. Geriatr. Psychiatry 2019, 34, 709-721. [CrossRef]

27. Luttenberger, K.; Hofner, B.; Graessel, E. Are the effects of a non-drug multimodal activation therapy of dementia sustainable? Follow-up study 10 months after completion of a randomised controlled trial. BMC Neurol. 2012, 12, 151. [CrossRef] [PubMed]

28. Jean, L.; Bergeron, M.-E.; Thivierge, S.; Simard, M. Cognitive Intervention Programs for Individuals With Mild Cognitive Impairment: Systematic Review of the Literature. Am. J. Geriatr. Psychiatry 2010, 18, 281-296. [CrossRef]

29. Viola, L.F.; Nunes, P.V.; Yassuda, M.S.; Aprahamian, I.; Santos, F.S.; Santos, G.D.; Brum, P.S.; Borges, S.M.; Oliveira, A.M.; Chaves, G.F.S.; et al. Effects of a multidisciplinar cognitive rehabilitation program for patients with mild Alzheimer's disease. Clinics 2011, 66, 1395-1400. [CrossRef]

30. Folstein, M.F.; Folstein, S.E.; McHugh, P.R. Mini-mental state. J. Psychiatr. Res. 1975, 12, 189-198. [CrossRef]

31. Roth, M.; Tym, E.; Mountjoy, C.Q.; Huppert, F.A.; Hendrie, H.; Verma, S.; Goddard, R.; Gartner, J.; Langford, A.; O'Brien, A.; et al. CAMDEX: A Standardised Instrument for the Diagnosis of Mental Disorder in the Elderly with Special Reference to the Early Detection of Dementia. Br. J. Psychiatry 1986, 149, 698-709. [CrossRef] [PubMed]

32. Schmand, B.; Walstra, G.; Lindeboom, J.; Teunisse, S.; Jonker, C. Early detection of Alzheimer's disease using the Cambridge Cognitive Examination (CAMCOG). Psychol. Med. 2000, 30, 619-627. [CrossRef]

33. Lawton, M.P.; Brody, E.M. ASSESSMENT OF OLDER PEOPLE. Nurs. Res. 1970, 19, 278. [CrossRef]

34. Reisberg, B.; Ferris, S.H.; De Leon, M.J.; Crook, T. The Global Deterioration Scale for assessment of primary degenerative dementia. Am. J. Psychiatry 1982, 139, 1136-1139. [CrossRef] [PubMed]

35. Davis, R.N.; Massman, P.J.; Doody, R.S. Cognitive Intervention in Alzheimer Disease: A Randomized Placebo-Controlled Study. Alzheimer Dis. Assoc. Disord. 2001, 15, 1-9. [CrossRef]

36. Hernández, C.R.; Unturbe, F.M.; Martínez-Lage, P.C.; Lucas, A.F.; Gil Gregorio, P.; Alonso, T.O. Efectos del tratamiento combinado de fármaco más estimulación cognitiva en la demencia moderada: Seguimiento de dos años. Rev. Española Geriatría Gerontología 2007, 42, 3-10. [CrossRef]

37. Suh, G.-H.; Ju, Y.-S.; Kil Yeon, B.; Shah, A. A longitudinal study of Alzheimer's disease: Rates of cognitive and functional decline. Int. J. Geriatr. Psychiatry 2004, 19, 817-824. [CrossRef]

38. Ballard, C.G.; O’Brien, J.T.; Morris, C.M.; Barber, R.; Swann, A.; Neill, D.; McKeith, I. The progression of cognitive impairment in dementia with Lewy bodies, vascular dementia and Alzheimer's disease. Int. J. Geriatr. Psychiatry 2001, 16, 499-503. [CrossRef]

39. Green, C.R.; Mohs, R.C.; Schmeidler, J.; Aryan, M.; Davis, K.L. Functional Decline in Alzheimer's Disease: A Longitudinal Study. J. Am. Geriatr. Soc. 1993, 41, 654-661. [CrossRef]

40. Alves, J.; Magalhães, R.; Machado, Á.; Gonçalves, Ó.F.; Sampaio, A.; Petrosyan, A. Non-pharmacological cognitive intervention for aging and dementia: Current perspectives. World J. Clin. Cases 2013, 1, 233. [CrossRef]

41. Talassi, E.; Guerreschi, M.; Feriani, M.; Fedi, V.; Bianchetti, A.; Trabucchi, M. Effectiveness of a cognitive rehabilitation program in mild dementia (MD) and mild cognitive impairment (MCI): A case control study. Arch. Gerontol. Geriatr. 2007, 44, 391-399. [CrossRef] 
42. Requena, C.; Maestú, F.; Campo, P.; Fernández, A.; Ortiz, T. Effects of Cholinergic Drugs and Cognitive Training on Dementia: 2-Year Follow-Up. Dement. Geriatr. Cogn. Disord. 2006, 22, 339-345. [CrossRef]

43. Germain, S.; Wojtasik, V.; Lekeu, F.; Quittre, A.; Olivier, C.; Godichard, V.; Salmon, E. Efficacy of Cognitive Rehabilitation in Alzheimer Disease: A 1-Year Follow-Up Study. J. Geriatr. Psychiatry Neurol. 2018, 32, 16-23. [CrossRef]

Publisher's Note: MDPI stays neutral with regard to jurisdictional claims in published maps and institutional affiliations.

(C) 2020 by the authors. Licensee MDPI, Basel, Switzerland. This article is an open access article distributed under the terms and conditions of the Creative Commons Attribution (CC BY) license (http://creativecommons.org/licenses/by/4.0/). 